\title{
Psychotic Disorder Due to a General Medical Condition
}

National Cancer Institute

\section{Source}

National Cancer Institute. Psychotic Disorder Due to a General Medical Condition. NCI

Thesaurus. Code C94392.

A psychotic disorder characterized by prominent hallucinations or delusions that have been determined to be etiologically linked to a general medical condition. 